\title{
La Reforma Tributaria del impUesto a la ReNTA PARA LAS PERSONAS NATURALES
}

\author{
Julio Trujullo Meza \\ Docente Facultad de Ciencias Contabbles
}

\begin{abstract}
RESUMEN
La Ley N..$^{\circ} 7904$ del Impuesto a la Renta del año 1936 representó uno de los mejores sistemas cedulares del Impuesto a la Renta; sin embargo, con el D.S. N. $.^{\circ} 287-68-\mathrm{HC}$ y el establecimiento del Impuesto a la Renta Global se modificó el sistema, mejorándolo sustantivamente al acumular todas las rentas en la cabeza del contribuyente; pero a partir del año 1993 y al crearse el Decreto Legislativo N. ${ }^{\circ} 774$ quedó vigente un Sistema Global Cedular, gravándose con la tasa del 30\% a las utilidades de las personas naturales con negocio.

En el análisis y vigencia de las normas del impuesto a la Renta, el Gobierno ha dictado normas sin considerar los principios constitucionales consagrados en el artículo $74^{\circ}$ de la Constitución Política del Perú, motivando la desnaturalización del Sistema del Impuesto a la Renta, tanto de la persona natural como de la persona jurídica y; de otro lado, al dictarse impuestos antitécnicos, esto ha traído como consecuencia que el Tribunal Constitucional resuelva favorablemente acciones de amparo y de inconstitucionalidad que dejan sin efecto la vigencia de varios tributos, demostrándose de esa forma la desnaturalización del Impuesto a la Renta, tanto de la persona natural como de la persona jurídica.

Todos están interesados en la modificación de la estructura tributaria del Perú, por lo que es conveniente la reimplantación del Impuesto al Patrimonio Neto Personal y del Impuesto al Patrimonio Empresarial que ya existieron en años pasados, conllevando inevitablemente la necesidad de postular, como consecuencia, una Reforma Estructural del Impuesto a la Renta que brinde seguridad jurídica.
\end{abstract}

Palabras clave: Sistema Cedular, Ley N. ${ }^{\circ} 7904$ del Impuesto a la Renta, Reforma Tributaria, Impuesto al Patrimonio Neto Personal.

\section{INTRODUCCIÓN}

La LeyN. ${ }^{\circ} 79041^{1}$ crea el Impuesto a la Renta en el Perú para las personas naturales y jurídicas, bajo el sistema "cedular o analítico" del Impuesto a la Renta que grava la renta en forma directa sobre el capital movible, las utilidades industriales y comerciales; las utilidades obtenidas en el ejerciciodelos profesionales nocomerciales, a los predios rústicos y urbanos; impuesto a los sueldos con tasas progresivas sobre la renta. Las tasas eran moderadas y afectaban a las rentas en forma equitativa bajo el principio tributario de "proporcionalidad" y bajo el criterio de afectar con menor impuesto las rentas originadas del trabajo

1 LeyN. ${ }^{\circ} 7904$, publicadael 26 de juliode 1934 y vigente desdeel $1^{\circ}$ deenerode 1935. 
personal; sin embargo, se distorsionó el sistema con la voracidad fiscal, por las urgencias económicas del Estado, siendo la Ley $\mathrm{N}^{\circ} 9103$ la que incrementó sustancialmente los impuestos a lossueldos, luego la Ley N. ${ }^{\circ}$ 9114, del 22 de mayo de 1940, duplicó la tasa del capital movible y se incrementaron las escalas de impuestos; así existieron luego otras disposiciones que distorsionaron el sistema que, como tal, inicialmente fue bastante bueno, serio, ponderado, claro, estructural hasta convertirlo en un conjunto de disposiciones conflictivas para luego ser derogados con el D.S. N. ${ }^{\circ} 287-68-\mathrm{HC}^{2}$ dictado al amparo de la LeyN. ${ }^{\circ} 17044$.

\section{SISTEMA GLOBAL DEL IMPUESTO A LA RENTA}

El D.S. N. ${ }^{\circ} 287-68-\mathrm{HC}$ estableció el "Sistema Global" del Impuesto a la Renta, derogando el "Sistema Cedular" para acumular en cabeza de un contribuyente todas las rentas de las diversas categorías y fuentes; de otro lado, diferenció la tributación paralas personas naturales y para las personas jurídicas. Durante, aproximadamente, quince años funcionó el sistema sin mayores problemas; sin embargo, nuevamente la voracidad fiscal distorsionó el sistema con leyes que lo hicieron complejo, dictándose el Decreto Legislativo N. ${ }^{\circ} 200^{2}$, publicado el 15 de junio de 1981, iniciándose el Sistema de "Retenciones" de Quinta Categoría con el D.S. N. ${ }^{\circ}$ 238-82$\mathrm{EFC}$, del 12 de agosto de 1982; posteriormente se dictó la Ley $\mathrm{N}^{\circ} 23509$ y se dieron una serie de disposiciones legales que no cambiaron el Sistema Global pero distorsionaron y complicaron el sistema en su aplicación, de modo que se dio mucho trabajo a los procesos de reclamo ante SUNAT y apelación ante el Tribunal Fiscal.

El Impuesto "Global o Sintético" sobre la renta total del sujeto es considerado como un impuesto ideal a cuya concreción deben orientarse las legislaciones en cuanto cumple cabalmente con los tributos del Impuesto a la Renta ${ }^{3}$.

\section{NUEVA ESTRUCTURA DEL SISTEMA GLOBAL-CEDULAR}

En el año 1993, se publica el Decreto Legislativo $\mathrm{N}^{\circ} 774^{4}$ y se pone en vigencia el $1^{\circ}$ de enero de 1994, cambiando el Sistema Global a un Sistema Global-Cedular, al extraer de las diversas categorías del Sistema Global, algunas rentas del trabajo, y tributar como renta cedular las personas naturales con negocio, los notarios, las sociedades civiles de profesionales con un criterio eminentemente recaudador, distorsionando el sistema tributario que respetaba los principios de proporcionalidad y de capacidad contributiva para que en un tiempo muy corto, de existir un Régimen General del Impuesto a la Renta bastante bueno, pasará a crearse una serie de impuestos distorsionantes dentro del sistema:

a) Impuesto a la Renta por el Régimen General (vigente).

b) Régimen Unico Simplificado - RUS (vigente).

c) Régimen Especial del Impuesto a la Renta - REF (vigente).

2 DecretoLegislativoN. ${ }^{\circ} 200$, publicado en el diario oficial El Peruano el 15 de juniode 1981.

3 GarcíaMullín:Manual del Impuestoala Renta, 1972.

4 DecretoLegislativoN. ${ }^{\circ} 774$, publicadoel 12 de diciembre de 1993 y vigenteapartir del $1^{\circ}$ deenero de 1994. 
d) Impuesto Mínimo a la Renta (derogado).

e) Impuesto Extraordinario a los Activos Netos (derogado).

f) Impuesto Extraordinario de Solidaridad (derogado).

g) Anticipo Adicional del Impuesto a la Renta (derogado)

h) Impuesto Temporal a los Activos Netos (vigente a partir del 01.01.2005).

La creación desproporcionada de los indicados impuestos distorsionó el llamado "sistema" para convertirlo en un "régimen" con fines eminentemente recaudatorios, en perjuicio del contribuyente. Es más, como consecuencia, se distorsiona y desnaturaliza el Sistema del Impuesto a la Renta de la Persona Natural y de la Persona Jurídica.

DESNATURALIZACIÓN DEL SISTEMA DEL IMPUESTO A LA RENTA DE LA PERSONA NATURAL

El Sistema del Impuesto a la Renta de la Persona Natural sedesnaturaliza, entreotras razones, fundamentalmente por:

a) Modificar el Sistema Global del Impuesto a la Renta y extraer de la tributación de dicho sistema a los notarios, las sociedades civiles de profesionalesy las personas naturalescon negocio para que tributen en forma separada y como si fueran empresas con una tasa fija proporcional del $30 \%$ sobre su renta neta, impuesto con el único objetivo de recaudación.

b) Las deducciones de las rentas de las diversas categorías con porcentajes (\%) fijos de las rentas de Primera, Segunda, Cuartay Quinta Categorías, sin medir los gastos inherentes y documentados que irrogan obtener cada una de las categorías, violando así el principio de capacidad contributiva.

En el Sistema del Impuesto a la Renta, la creación de una serie de impuestos antitécnicos e inconstitucionales que terminaron por ser derogados y ser declarados inconstitucionales. La distorsión se concreta al crearse los respectivos impuesto violando el artículo $74^{\circ}$ de la Constitución Política del Estado, es decir, los principios de legalidad, igualdad y no confiscatoriedad, además el respeto a los derechos fundamentales de las personas; situación que fue confir mada por el Tribunal Constitucional en pronunciamientos reiterados, quedando el Impuesto Temporal a los Activos Netos ${ }^{5}$ que, igualmente, no difiere de los creados antes y con seguridad se presentarán acciones de amparo por ser, aparentemente, incoherente con la existencia del Impuesto a la Renta-Régimen General.

\section{REFORMA INTEGRAL Y ESTRUCTURAL DEL SISTEMA DEL IMPUESTO A LA RENTA DE LA PERSONA NATURAL}

La situación del país requiere una reforma total y estructural del Impuesto a la Renta, tanto para las personas naturales como jurídicas, a fin de volver a instaurar un "sistema" de impuestos directos e indirectos, técnico-legal, que respete los principios doctrinarios y constitucionalesen materia tributaria y los principios de generalidad, neutralidad, proporcionalidad, causalidad, razonabilidad y, sobre todo, el principio de capacidad contributiva, obviamente partiendo de un nuevo modelo

\footnotetext{
${ }^{5}$ LeyN. ${ }^{\circ} 28424$, publicada el 21/12/2004, vigente a partir del 01/01/2005 hasta el 31/12/2006.
} 
económico que proporcione rentas, patrimonios y consumos al contribuyente suficientes, que per mitan contribuir con los tributos, sin que ello signifique un sacrificio o una exacción que afecte su patrimonio personal o su renta de supervivencia.

En este marco de una reforma estructural, al reformarse el Impuesto a la Renta de las personas naturales, se hace necesario evaluarse el retorno al sistema técnico del impuesto por el sistema global, ya que este sistema atiende a la totalidad de la capacidad contributiva del sujeto, por cuanto abarca la globalidad de sus ingresos, puesto que todas las rentas que existen en la economía se atribuyen a las personas físicas, de modo que ninguna escapa de la imposición a ese nivel, con las deducciones inherentes a cada rentagravada y que sirvan, dichas deducciones, al mantenimiento de la renta gravada o al incremento de la misma.

\section{CREACIÓN DEL IMPUESTO AL PATRIMONIO NETO PERSONAL EN EL PERÚ}

Es necesario llegar a la imposición del Impuesto al Patrimonio Neto Personal, si bien escierto que este tributo existió primero con el Decreto Legislativo N. ${ }^{\circ} 451^{6}$, creado para ser aplicado a partir del Ejercicio 1988 y su Decreto Supremo N. ${ }^{\circ} 176-88-E F$, ampliatorias, modificatorias y normas conexas, aparentemente no fue del agrado de ciertos grupos económicos, siendo derogado por el DecretoLegislativoN. ${ }^{\circ} 620$, sin haber tenido mayor evaluación.

En el Perú, en un segundo intento por reimplantar el Impuesto al Patrimonio
Personal, se dictó el Decreto Legislativo N. ${ }^{\circ}$ 620 , con vigencia a partir del $1^{\circ}$ de enero de 1991; se crea dicho impuesto "gravando el patrimonio establecido en el país determinado al $1^{\circ}$ de enero de cada ejercicio gravable, de propiedad de las personas naturales, sociedades conyugales y sucesiones indivisas"".

El dispositivo legal contiene quince artículos y dos disposiciones finales; sin embargo,suduración fuedecortotiempo, pues se derogó en 1993 en forma conjunta con el DecretoLegislativoN. ${ }^{\circ} 619$, sobreel Impuesto al Patrimonio Empresarial, y se implantó el llamado Impuesto Mínimo a la Renta.

En ese orden de ideas es perfectamente posible que se restablezca el Impuesto al Patrimonio Neto Personal teniendo en cuenta los antecedentes y la vigencia del mismo en España.

El Perú, generalmente desde hace algunos años, viene importando los sistemas y formas impositivas deEspaña, por elloesconveniente recordar al Gobierno que en España está vigente el "Real Decreto Legislativo 3/2004", del5demarzo,ysureglamentoel Real Decreto 214/1999, del 5 de febrero, que pone en vigencia la Ley del Impuesto sobre la Renta de las Personas Físicas y su Reglamento correspondiente; y desde el 6 de junio de 1991 se crea la "Ley 19/1991 del Impuesto sobre el Patrimonio", con el propósito de que la persona natural declare todos sus bienes patrimoniales en vinculación con el Impuesto a la Renta de la Persona Jurídica.

Este tributo tiene íntima vinculación con el Impuesto a la Renta, puesen la medida en que se declare una mayor renta es posible

6 DecretoLegislativoN. ${ }^{\circ} 451$, publicado el 31dediciembre de 1987, Impuesto que Gravael Patrimonio Netodelas Personas Naturales y Sucesiones Indivisas.

7 DecretoLegislativoN. ${ }^{\circ}$ 620, publicadoel31/11/1990, vigente apartirdel $1^{\circ}$ de enero de 1991. 
que pueda justificar el incremento patrimonial que responda a ello; sin embargo, hoy observamos que en muchos casos existen incrementos patrimoniales que no se justifican con la Declaración Jurada del Impuestoa la Renta dela persona natural. Hoy la persona natural solo paga el Impuesto Predialy Automotriz, que no es significativo, y deja de declarar todos los demás bienes de considerable valor.

\section{EL IMPUESTO AL PATRIMONIO NETO PERSONAL EN ESPAÑA}

España dictó la "Ley 50/1977 del 14 de noviembre, sobre medidas urgentes de Reforma Fiscal"y dentro de ellos estableció, con carácter excepcional, el transitorio ImpuestoExtraordinariosobreelPatrimonio de las Personas Físicas y con la nueva Ley del año 1991, se hace permanente con una función de carácter censal y de control del Impuesto a la Renta de las Personas Físicas, asumiendo así los objetivos de una mayor eficacia en la utilización de los Patrimonios y la obtención de una mayor justicia redistributiva complementaria de lo aportado por el Impuesto a la Renta de las Personas Físicas ${ }^{8}$.

\section{ESTUDIO PARA CREAR EL IMPUESTO AL PATRIMONIO NETO PERSONAL EN EL PERÚ}

El Gobierno y la Administración Tributaria deben coordinar a fin de establecer el Impuesto al Patrimonio Neto Personal, porque se mediría con mayor efectividad la capacidad contributiva de las personas y, de esta for ma, establecer técnica y legalmente un sistema que controle la evasión en el caso de las personas naturales, que los incrementos patrimoniales correspondan a sus rentas declaradas, estableciendo un sistema de declaraciones de bienes cuyos valores tengan representación y significación, una deter minación de la base imponible técnica, una escala del impuesto progresivo, procurando con ella medir la capacidad contributiva de las personas. En suma, considerar que se tienen antecedentes en el propio país para poner en vigencia este tipo de tributos; de ser el caso, tomar la experiencia de España, cuyo tributo tiene más de diez años de vigencia positiva y el Sistema del Impuesto a la Renta de Personas Físicas funciona como un control del Impuesto al Patrimonio de las Personas Físicas.

\section{REFORMA ESTRUCTURAL E INTEGRAL DEL SISTEMA TRIBUTARIO PERUANO}

Es urgente una reforma estructural $\mathrm{e}$ integral del Sistema Tributario Peruano. Es cierto que se ha reducido la cantidad de tributos, pero el sistema ha sido distorsionado y desnaturalizado; no olvidemosqueel DecretoSupremoN. ${ }^{\circ} 287$ 68-HC estableció un sistema que duró, aproximadamente, trece años. El Sistema TributarioPeruano puedeser perfeccionado en cuanto se refiere al Impuesto a la Renta de Personas Naturales; sin embargo, desde dicha fecha los Gobiernos de turno prefirieron la recaudación, desnaturalizando el Sistema del Impuesto a la Renta como sistema y distorsionándolo con una serie de leyes incoherentes que buscaban una mayor recaudación en perjuicio del contribuyente. No olvidemos que durante el Gobierno

8 CentrodeEstudiosFinancieros. ImpuestossobrelaRentasdelasPersonas FíscasysobreelPatromorno. 12. ${ }^{\mathrm{a}} \mathrm{ed}$, Ediciones CEF,2004. 
anterior, en el año 1994, se rompió el sistema y se convierte eminentemente recaudatorio y sancionatorio, creando disposiciones violatoriasde los principios constitucionales. El actual Gobierno ha seguido con el Régimen, distorsionándolo completamente con la creación de tributos antitécnicos, que han merecido ser derogados con acciones de amparo y de inconstitucionalidad. Creemos que el actual Gobierno ya no podrá hacer ninguna reforma tributaria, corresponderá al Gobierno siguiente el ordenamiento del modelo económico y la implantación de un "Sistema Tributario Integral", que respete los principios doctrinarios y constitucionales así como los principios tributarios referidos al Impuesto a la Renta de las Personas Naturales", salvo que el Congreso rescate su labor legislativa y pueda instaurar una Reforma Tributaria Integral que procure los recursos necesarios para la Hacienda Pública, sin afectar la economía de las personas y respetando los principios doctrinarios y constitucionales tan venidos a menos en la actualidad.

\section{CONCLUSIONES Y RECOMENDA- CIONES}

a) Debemos formular un Sistema de Impuesto Global paraconstituirun sistema que mida con equidad la capacidad contributiva de la persona natural.

b) Debemos implantar nuevamente el Impuesto al Patrimonio Neto Personal para obtener mayores recursos y reducir la tasa del Impuesto General a las Ventas, con la finalidad de lograr una mayor reactivación de la economía y sirva como un mecanismo de control en la recaudación del Impuesto a la Renta de las personas naturales.

c) Debemos propiciar una reforma estructural y total del Sistema Tributario, considerando los aspectos doctrinarios y constitucionales en materia tributaria; obviamente teniendo en cuenta un modelo económico que proporcione las suficientes rentas, patrimonio yconsumos.

d) Recomendamos que para los efectos de la Reforma Tributaria se acuda a los organismos especializados como el IPIDET, el IPDT, el IFA y los Colegios Profesionales que tienen que ver con la materia tributaria.

\section{REFERENCIAS}

1. CentrodeEstudios Financieros. Impruestos sobre la Renta de las personas físicas y sobre el patrimonio. 12. ${ }^{\text {a }}$ ed., Ediciones CEF, 2004.

2. García Mullín. Manual del Impuesto a la Renta. 1972.

3. Diario oficial El Peruano. Decreto Legislativo N. ${ }^{\circ} 200$ (15/06/1981).

4. Diario oficial El Peruano. Decreto Legislativo N. ${ }^{\circ} 451$ : Impuesto que Grava el patrimonio netodelas personasnaturales y sucesiones indivisas (31/12/1987).

5. Diario oficial El Peruano. Decreto Legislativo N. ${ }^{\circ}$ 620: Ley del Impuesto a la Renta (31/11/1990).

6. Diario oficial El Peruano. Decreto Legislativo N. ${ }^{\circ} 774$ : Ley del Impuesto a la Renta (12/12/1993)

7. Diario oficial El Peruano. Decreto Supremo N. ${ }^{\circ}$ 287-68-HC: Texto único del Impuesto a la Renta, al valor de la propiedad predial y al patrimonio accionario (09/ 08/ 1968).

8. Diario oficial El Perzmo. LeyN. ${ }^{\circ} 7904$ : Ley del Impuesto a la Renta para las personas naturales y jurídicas (26/07/1934).

9. Diario oficial El Perumo. LeyN. ${ }^{\circ} 28424$ : Impuesto Temporal a los Activos Netos (21/12/2004).

9 En el próximo artículo dela Revista Juris abordaremoslasituación dela tributación delas personas jurídicas. 